\title{
In-service Zimbabwean teachers' views on the utility value of diagrams in the teaching and learning of geometry
}

\author{
Gladys Sunzuma, Cecilia Chando, Isaac Gwizangwe, Nicholas Zezekwa and \\ Gracious Zinyeka
}

Bindura University of Science Education, Zimbabwe

\begin{abstract}
Geometry is an essential component of mathematics which promotes the development of critical thinking and problem-solving skills. Geometry shapes are an integral part of our lives. This study focused on the teachers' practices, specifically on how teachers ought to be equipped with a good understanding of the effectiveness of the use of diagrams in geometry teaching and learning. A mixed-method approach comprising of questionnaires and interviews was used in this study. Ninety-one teachers participated in this study. The research findings were categorized using the four themes of utility, positive attitudes, negative attitudes, and teachers' use of diagrams in geometry class. The study showed that diagrams are effective in the teaching and learning of geometry concepts. It is recommended that teachers could do well if they make use of technology in designing diagrams to be used in the teaching and learning of geometry.
\end{abstract}

Keywords: geometry, diagrams, teaching, learning
Article Details

LUMAT General Issue

Vol 8 No 1 (2020), 1-18

Received 18 November 2019

Accepted 19 March 2020

Published 30 March 2020

Pages: 18

References: 44

Correspondence:

gsunzuma@gmail.com

https://doi.org/10.31129/ LUMAT.8.1.1316

\section{Introduction}

Mathematics is one of the most important school subjects in the curriculum worldwide. It is a subject that has a direct relationship with other subjects, particularly in the technical and scientific areas. Mathematics also cuts across primary and secondary schools as a compulsory subject in Zimbabwe. In the Zimbabwean mathematics syllabus (2015-2022), geometry is one of the major topics which covers almost three-quarters of the syllabus. Geometry is the main branch of mathematics, and its content is classified into four areas (Ndinda, 2016). Firstly, plane geometry is the component that deals with figures in the two-dimensional plane. Secondly, solid geometry focusing on figures in three-dimensional space. Thirdly, spherical geometry that focusses on figures on the surface of the sphere. Lastly, the Euclidean geometry that focusses on plane and solid based on Euclid's postulates and Analytical geometry that focusses on the connection between algebra and geometry, using graphs and equations of lines, curves, and surfaces to develop and prove relationships.

In the Zimbabwean mathematics syllabus (2015-2022), the common topics in geometry are plane geometry, solid geometry, transformation geometry, and analytical geometry. However, it is a challenge to note that with the wide coverage of 
geometry in the syllabus and the importance attached to it in Zimbabwe's education system, poor performance is recorded in geometry questions in the public examinations, which results in poor performance in mathematics. Since science and mathematics have turned out to be a crucial feature in social progress and national trade and industry, poor attainment in the mathematics subject is likely to impact negatively on scientific research, as well as trade and industry in developing nations such as Zimbabwe (Economic and Social Research Council, 2008). Mathematics and science education is perceived as a means of creating a critical mass of scientists and scientifically knowledgeable citizenry (Sjøberg \& Schreiner, 2005) which is considered needed for an improved financial system and emancipation from social ills such as crime and disease, poor quality of life and poverty in general (Zinyeka, 2016).

There could be numerous causes why the majority of candidates who sit for public examinations in Zimbabwe do not achieve well in mathematics in the area of geometry. These reasons may be resulting from several sources. For example, those originating from the learners themselves such as absence of interest, poor language facility, poor motivation, the abstract nature of mathematics, learner worldviews that might be in clash with the ways of knowing in science and mathematics say (Zinyeka, 2016; Abrams, Taylor \& Guo, 2013; Aikenhead, Calabrese \& Chinn, 2006). Other causes may have to do with teacher factors, such as teachers' lack of effective ways of teaching, poor experience, qualifications and an insufficient knowledge base of teachers, as well as non-educational dynamics such as under-resourced large size classes (Mashingaidze, 2012; Telima, 2011; Chiwiye, 2013). This paper's research interest, however, is to contribute to the advocacy for use and full utilization of diagrams in the teaching and learning of as one way of supporting teachers to improve on learners' performance.

However, researchers have proposed various ways of improving the teaching and learning of geometry such as genetic approaches involving historical, logical and epistemological, psychological and socio-cultural aspects (Safuanov, 2007); ethnomathematical and humanist approaches that value culture and scientific heritage (Gerdes, 2011); using artwork as an innovative instrument to teach geometry concepts (Pakang \& Kongtaln, 2007), as well as the use of diagrams and examples (Zodik \& Zaslavsky, 2007). Despite several suggestions by researchers, learners' performance remains poor in geometry. Zodik and Zaslavsky (2007) and Stylianou (2002), cited in Jones (2013) reported on the lack of evidence on the effective utilization of diagrams in the teaching and learning of geometry by teachers. However, the utilization of diagrams by teachers and more fundamentally, their knowledge with regards to the 
effectiveness of the use of diagrams in the teaching and learning of geometry remains unclear (Jones, 2013). This study focuses on teachers' views on the utility value of diagrams in the teaching and learning of geometry. In particular, the study seeks to address the following research questions and hypothesis:

1. What are the Zimbabwean teachers' views on the utility value of diagrams in the teaching and learning of geometry?

2. Is there a significant difference between rural and urban Zimbabwean teachers' views on the utility value of diagrams in the teaching and learning of geometry?

3. How are Zimbabwean teachers using diagrams to teach geometry?

\section{Diagrams in geometry teaching and learning}

Geometry continues to play a central role in modern mathematics applications; nonetheless, its concepts have become increasingly diagrammatic. It is one aspect of mathematics education that comprises the largest use of diagrams (Watson, Jones \& Pratt, 2013). Purchase (2014, p. 59) defined a diagram as "taken to mean a composite set of marks (visual elements) on a two-dimensional plane that, when taken together, represent a concept or object in the mind of the viewer." Diagrams are 2D geometric figurative exemplification of data according to some visualization method, and at times, the method uses a $3 \mathrm{D}$ visualization that might be projected onto the $2 \mathrm{D}$ surface. Diagrams are visual illustrations of figures that are used to pass on information.

Gagatsis, Deliyianni, Elia, Monoyiou \& Michael (2010) observed that geometry problems call for interaction with diagrams as well as making the use of picturing to identify the figures and their properties. The aptitude to use diagrammatic shapes to deduce appropriate geometry content knowledge in problem-solving is an indication of one's strong competency in geometry (Koedinger \& Anderson, 1990). Jones (2001) was also of the view that diagrams contribute to problem-solving skills in geometry. Diagrams improve learners' reasoning skills in geometry (Herbst, 2004). They enhance the development of mathematical processes such as analytical, visual, and logical thinking (Jones, 2001). Diagrams also provide an opportunity for logical thought, critical thinking, elucidation, and explanation for solving geometric problems. In fact, diagrams enhance conceptual understanding and conception of geometry concepts, operations, and relations. For example, students may identify and appreciate the meaning of symbols, words, and relationships with a specific concept and use diagrams to build new geometry knowledge (Novick, 2004). Diagrams are a semiotic method of representation and communication that allows for the 
construction of geometrical meaning. Diagrams are a mode of communication in geometry. Diagrams play an important role in the construction of knowledge, argumentation, and understanding of geometry. Diagrams are employed as a method to visualize geometry concepts as well as in studying the meaning in geometry (Dimmel \& Herbst, 2015). The following is an example of such a diagram that can be used to teach geometry concepts.

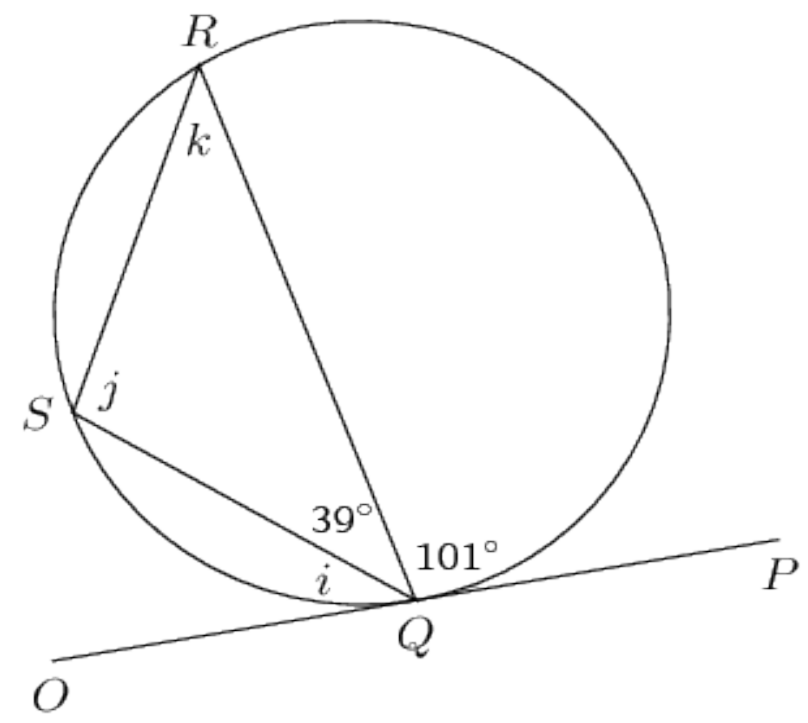

Find the angles $i, j$, and $k$.

Figure 1. Geometry diagram. Source: ZIMSEC (2016) past examination paper.

There are numerous benefits of using diagrams in the teaching and learning of geometry. Gagatsis et al. (2010) noted that geometrical diagrams are simultaneously concepts and spatial representations of abstract ideas. Diagrams in two-dimensional geometry may illustrate theoretical geometrical properties, or they might offer spatiographical properties, which may result in student's perceptual and critical thinking skills and activities if taught well. According to Herbst (2004), an interaction with diagrams creates possible chances of coming up with reasoned conjectures. Jones and Tzekaki (2016) thought that diagrams are tools to create examples that support conjectures; they are used to design and describe the domain and context of the task. Diagrams enable direct manipulations by providing feedback that reflects the process of inquiry. Diagrams bring some variety in clarifications of problems. Such a multiplicity of functions may give students opportunities to take part in fruitful inquiry as well as the aptitude to formulate and solve geometry problems (Butcher \& Aleven, 2008). In addition, diagrams help directly in the cognitive process as well as engaging the students, thereby increasing their interest, which can translate into 
geometrical ability (Butcher \& Aleven, 2008). Hence, teachers need to methodically incorporate diagrams in the teaching and learning of geometry so as to develop students' geometrical proficiency and critical thinking.

According to Jones (2013), diagrams are considered to be an essential element of doing and understanding mathematics in general and geometry in particular. Their application is not solely on the nature of geometrical objects, but also to improve the effective problem representation that enables complex geometric process and structures to be represented holistically. Diagrams offer the possibility of altering the approach in geometry teaching from the sequential, lingual to the visual-spatial presentation. All components of the display are presented concurrently, and analysis involves visual reasoning.

Diagrams allow both the teacher and the learner to view the problem in its totality as all parts of the problem are displayed on the diagram at the same time. Diagrams also offer teachers and learners an advantage of moving between diverse observations by viewing the complete diagram or some portions of it, which is crucial in arriving at alternative solutions to a problem. Diagrams are often a good starting point for solving geometry problems (Bishop, 1989; Jones, 2001).

Jones and Tzekaki (2016) noted that diagrams are worth a million in words, and reading from diagrams is helpful for students to understand geometry. In Zimbabwe, as in many other countries, the English language, which is the instructional language used for teaching and examinations, is a second language for both teachers and learners. As a result, in most cases, it is difficult to teach geometry concepts without diagrams. From this point of view, diagrams are useful in representing the information presented in the geometry images in ways that verbal language may not explain fully (O'Halloran, 1999 in Dimmel \& Herbst, 2015). Diagrams act as a complementary language to written text and symbolic language of geometry.

One other important benefit of using diagrams in the teaching and learning of geometry is that it enhances conceptual understanding. Conceptual understanding, critical thinking, and effective problem-solving in geometry depend on students' understanding of the shape, size as well as on the properties of various figures (NCTM, 2000). Hence, using diagrams is crucial for effectively setting up as well as solving geometry problems (NCTM, 2000). These diagrams enable students to show and deduce the essential components of geometry problems throughout the problemsolving process (NCTM, 2000). Conceptual understanding is positively correlated with higher achievement in geometry (Bailey, 2013). Diagrams have a significant impact on students' geometry achievement; hence, there is a need to improve their 
conceptual knowledge through the use of diagrams (Bailey, 2013). Jones and Tzekaki (2016) were of the view that diagrams help in retaining of geometry knowledge and skills. The appropriate use of diagrams in the teaching and learning of geometry supports long-term knowledge retention of problem-solving skills (Butcher \& Aleven, 2008). Yelland and Masters (2007) denoted the term cognitive scaffolding to the use of diagrams that helps in the development of conceptual and procedural understandings and encouraging students to work together with their partner. Diagrams support students in understanding the association of abstract concepts, such as transformation and its meaning.

As facilitators of student learning, teachers confess that diagrams are essential tools for solving problems and that diagrams aid in grounding the study of abstract geometric objects in specific realizations that are available to students (Dimmel \& Herbst, 2015). Teachers depend on diagrams to communicate properties of order, incidence, and separation (Dimmel \& Herbst, 2015) for the reason that an entirely overall treatment of such properties could make the previously challenging work of learning to write proofs even further demanding for students.

Jones (2013) views diagrams in geometry as based on the observation that generalizes facts. Students interact with the diagrams whilst investigating the situations under which the type of geometry problem can be answered (Herbst \& Arbor, 2004). Matos and Rodrigues (2011) investigated how the construction of geometric proof related to the social practice developed in the classroom, and, in particular, the role of geometric diagrams. Further, they concluded that diagrams played "an important role in the process of sharing and increasing the ownership of the meaning of proof by highlighting the relevant properties" (p. 183). Diagrams in geometry are an example of a constructivism approach of learning which fosters critical thinking, and students make connections from concrete to abstract. According to Fosnot (1996), diagrams are grounded in the constructivism philosophy, where more emphasis is put on connecting learning content to the real world for the reason that knowledge is developed in the context of the student's surroundings.

Bieda (2011) reported on the aspects of proofs and non-proofs that were convincing to middle-grade students. The analysis found that the students "valued the explanatory power of a valid argument when evaluating a proof for a true geometry statement that provided a diagram" (p. 153). Teachers were of the view that diagrams can improve the teaching and learning of geometry as well as encouraging the students to reflect on the fundamental concept (Puphaiboon \& Woodcock, 2005). Konyalioglu, Isik, Kaplan, Hizarci, and Durkaya's (2011) study revealed that the use 
of diagrams made lessons fascinating, motivating, thereby removing boredom from the learners. In addition, in the same study, most of the learners pointed out that they saw the necessity of visualization, specifically the use of diagrams, whether they were drawn or produced by technology. Üstün and Ubuz (2004) reported that the use of dynamic images improved the learning of geometry concepts. In addition, the same authors found that learners also developed strategies to form links between the geometry shapes and also formed hierarchical\| connection between the shapes.

Diagrams are essential in geometrical thinking, whether they are produced using technological devices, imagined or drawn on papers, and they capture the utmost essential features of the geometrical problem as well as providing the possible solution (Alcock \& Simpson, 2004). Diagrams are an important component of the concrete images and are vital to the cognitive process. According to Puphaiboon and Woodcock (2005), understanding a diagram is a component of the thinking process that joins design formation with the symbol aspects of geometry. Diagrams are synonymous with geometrical thinking and reasoning. Small (2012) states that:

Diagrams either with or without accompanying words, can be extremely powerful tools for reasoning and explaining; they are powerful not only because they help us understand more quickly, but also because sometimes they lead us to be more general than when we use specific numerical examples. (p. 21)

From this statement, diagrams are likely to make mathematical explanations simpler as well as leading to generalities quickly. Diagrams have the potential of providing students with rapid visual access to the whole system of quantifiable relationships defined in the problem. Hence, the use of diagrams promotes a holistic vision of the problem for students.

The use of diagrams also promotes a deeper, abstract understanding of mathematic concepts (Limin Jao, 2013; Prusak, Hersckowitz \& Schwarz, 2012). The benefits of diagrams are ascribed to the process of transforming a mathematics idea from one form into another, where learners are provided with alternative forms of illustrations of the same knowledge. They might turn out to be more motivated to make sense of it (Panasuk \& Beyranevand, 2010). In addition, diagrams are useful in transforming word language of geometry concepts, definitions as well as proposition into geometrical symbol language (Ding, Jones \& Zhang, 2013).

Despite the numerous benefits of using diagrams in the teaching and learning of geometry, researchers such as Jones and Tzekaki (2016) reported on obstacles on the use of diagrams in geometry both for students and teachers. They noted that in some 
situations, the diagrams might even distract students from their conceptual or appropriate hypothetical knowledge. Jones, Fujita, and Kunimune (2012) conducted a study involving secondary school students tackling a 3-D geometry problem that used a specific diagram as an image of a cube. The study findings showed that some of the students could "take the cube as an abstract geometrical object and reason about it beyond reference to the representation," while others needed to be offered "alternative representations to help them 'see' the proof" (p. 339). Haj-Yahya and Hershkowitz (2013) carried out a study with the aim of "linking visualization, students' construction of geometrical concepts and their definitions, and students' ability to prove" (p. 409). The study showed that many of the students knew the formal definitions of various shapes but could not use the definitions when given problems that required the use of diagrams. Diagrams provide an instantiation of a definition, not a universal and demanding proof that enables students to concentrate on the figural understanding that results in conceptual understanding (Jones, \& Tzekaki, 2016).

If the diagrams are poorly designed, they are not effective in the teaching and learning of mathematics in general and geometry in particular (Jones \& Mooney, 2003). Typical problems such as information not being structured to denote vital concepts or stages so as to point out the geometrical concepts involved, as well as the inability of diagrams to support spatial and pictorial reasoning (Jones \& Mooney, 2003), makes the use of diagrams ineffective. The use of inappropriate and misleading diagrams may contribute to problems in the teaching and learning of geometry. For instance, if incorrect diagrams are used in the teaching and learning of geometry, they tend to confuse the students who will be struggling to learn new concepts (Puphaiboon \& Woodcock, 2005). Superficial and diverted attention to information on diagrams might compromise the ability to solve problems (Butcher \& Aleven, 2008). In addition, Leung and Park (2009) found that geometry language and daily language both support and inhibit students' understanding of shapes and their properties since the terms force students to focus on some exceptional features that are not in line with the definition of the shapes. 


\subsection{Research design}

Due to the nature of the problem under study, a mixed research paradigm was adopted, where both qualitative and quantitative research approaches were used. A mixed research paradigm was used in this study because it provides strengths that offset the weakness of both qualitative and quantitative. Mixed approaches also provide a more complete and comprehensive understanding of the research problem than either quantitative or qualitative only (Angell \& Townsend, 2011).

\subsection{Population and Sample}

Ninety-one secondary school mathematics teachers who were attending a one-day inservice teacher training workshop on the use of latex in mathematics education completed the questionnaires before the commensuration of the workshop. The questionnaires were the first data source to gather data on teachers' views on the use of diagrams in the teaching and learning of geometry. The participating teachers were from a different school situated in rural and urban, where some schools are underresourced whilst others are well-resourced. As a result, the participants and their schools were representatives of the schools in the province under study.

The second source of data consists of interviews with five teachers from different schools. The interviews allowed the teachers to spell out their views on the use of diagrams in the teaching and learning of geometry in secondary schools. One of the courses offered at the university is practicum teaching, which is done in some schools in the province. The five teachers interviewed were those where student teachers visited by the researchers during their appraisal and supervision. Hence, the interviewed teachers might be regarded as purposively selected for the reason that the teacher that was found at an attachment school on a particular day of the visit and that the school that was visited sent a teacher to take part in the workshop in which teachers completed the questionnaires for this study.

\subsection{Data collection methods}

In this study, data was collected using interviews and questionnaires. The questionnaires that were used to collect data were informed of closed-ended questions with two responses: Agree and disagree. Although it is generally agreed that a large number of response categories in Likert scale items improves the psychometric 
properties of a scale, a reduced number of response categories may possibly have a positive effect on the validity of gathered data by reducing the number of chances for incorrectly treating different views of response categories as if they were the same (Jones \& Scott, 2013). Hence, fewer response categories are adequate, depending on the purpose and scope of the study (Jones \& Scott, 2013). The participants were, therefore, asked to respond to the questionnaire with two categories, agree (A) and disagree (DA). Questionnaires were used because a large number of participants can be reached, they are easier to use, and they provide quantifiable answers that are relatively easy to analyse. Questionnaires were self-administered. Interviews helped the researchers to gather data that is detailed and rich to the topic under the study. The interviews were tap-recorded.

The validity and reliability of this research are strengthened by triangulation through using different data sources, for example, interviews and questionnaires. Pilot testing was conducted at a satellite school in the district with 5 participants in order to test suitability, problems, and barriers to the study area and feasibility of research instruments so as to improve the validity and reliability of the instruments used.

\subsection{Data analysis}

For statistical analysis, the data from the questionnaires were statistically analyzed using SPSS (Statistical Package for Social Sciences, version 20). A non-parametric test such as Mann-Whitney Test (U) was used to further analyse the data. A significance level of $\mathrm{p}=0.05$ was used. The interview data were later transcribed in full and were also analysed.

\section{Findings and discussion}

The results of this study were presented according to the approaches used for data gathering. Results from the questionnaires were presented first, followed by those from interviews.

\subsection{Data from questionnaires}

Frequencies and percentages of the teachers' responses were arranged in descending order with the aim of determining the popularity of the teachers' responses on each category. Table 1 shows the responses of the teachers' views on the utility value of diagrams in the teaching and learning of geometry, which were categorised as 
utilitarian value and positive attitude.

Table 1. Teachers' responses on the utility value of diagrams in the teaching and learning geometry ( $\mathrm{n}=91)$ ( $A=$ agree, $D A=$ disagree).

\begin{tabular}{|c|c|c|c|}
\hline Item & Narration & A & DA \\
\hline \multicolumn{4}{|c|}{ Utilitarian value } \\
\hline 13 & $\begin{array}{l}\text { Geometry diagrams help students to acquire important information and } \\
\text { skills }\end{array}$ & $\begin{array}{l}90 \\
(98.9)\end{array}$ & $\begin{array}{l}1 \\
(1.1)\end{array}$ \\
\hline 5 & $\begin{array}{l}\text { Diagrams develop students' procedural literacy in solving geometry } \\
\text { problems and investigations in geometry }\end{array}$ & $\begin{array}{l}88 \\
(96.7)\end{array}$ & $\begin{array}{l}3 \\
(3.3)\end{array}$ \\
\hline 4 & Geometric diagrams enhance the teaching and learning of geometry & $\begin{array}{l}86 \\
(94.5)\end{array}$ & $\begin{array}{l}5 \\
(5.5)\end{array}$ \\
\hline 9 & $\begin{array}{l}\text { Diagrams are used to analyse a problem logically and reach conclusions } \\
\text { quickly }\end{array}$ & $\begin{array}{l}85 \\
(93.4)\end{array}$ & $\begin{array}{l}6 \\
(6.6)\end{array}$ \\
\hline 1 & Diagrams can be used to help learners perform better in geometry & $\begin{array}{l}73 \\
(80.2)\end{array}$ & $\begin{array}{l}18 \\
(19.7)\end{array}$ \\
\hline 11 & $\begin{array}{l}\text { Geometry diagrams are used to build on already assumed geometry } \\
\text { concepts }\end{array}$ & $\begin{array}{l}67 \\
(73.6)\end{array}$ & $\begin{array}{l}24 \\
(26.4)\end{array}$ \\
\hline \multicolumn{4}{|c|}{ Positive attitude } \\
\hline 10 & Students constantly connect mathematical ideas when using diagrams & $\begin{array}{l}88 \\
(96.7)\end{array}$ & $\begin{array}{l}3 \\
(3.3)\end{array}$ \\
\hline 8 & $\begin{array}{l}\text { Geometry diagrams usually display a variety of properties and strategies for } \\
\text { problem-solving. }\end{array}$ & $\begin{array}{l}87 \\
(95.6)\end{array}$ & $\begin{array}{l}4 \\
(4.4)\end{array}$ \\
\hline 3 & Diagrams have a higher impact on retention of geometry concepts & $\begin{array}{l}87 \\
(95.6)\end{array}$ & $\begin{array}{l}4 \\
(4.3)\end{array}$ \\
\hline 12 & $\begin{array}{l}\text { Geometric diagrams attach student s' prior experiences to his / her learning } \\
\text { geometry topics }\end{array}$ & $\begin{array}{l}78 \\
(85.7)\end{array}$ & $\begin{array}{l}13 \\
(14.3)\end{array}$ \\
\hline 2 & There is a greater achievement for learners who use diagrams in geometry & $\begin{array}{l}64 \\
(70.3)\end{array}$ & $\begin{array}{l}27 \\
(26.9)\end{array}$ \\
\hline 6 & Diagrams make learners develop a good attitude towards geometry concepts & $\begin{array}{l}59 \\
(64.8)\end{array}$ & $\begin{array}{l}32 \\
(31.2)\end{array}$ \\
\hline 14 & $\begin{array}{l}\text { Geometric diagrams can effectively transfer the challenging work to new } \\
\text { understandable situations }\end{array}$ & $\begin{array}{l}56 \\
(61.5)\end{array}$ & $\begin{array}{l}35 \\
(38.5)\end{array}$ \\
\hline 7 & There is a relationship between geometry and diagrams & $\begin{array}{l}48 \\
(53)\end{array}$ & $\begin{array}{l}43 \\
(47)\end{array}$ \\
\hline
\end{tabular}

Teachers in this study held positive views about the utilitarian value of diagrams in the teaching and learning of geometry. The response percentages range from 73.6 (Item 11, Table 1) to 98.9 (Item 13, Table 1) for those who agreed. Those positive utilitarian values show how teachers regard the use of diagrams as useful in the teaching and learning of geometry. The views held by those teachers in this study are in line with (Jones, 2013; Jones \& Tzekaki, 2016; Dimmel \& Herbst, 2015) who were of the view that the integration of diagrams in geometry might be helpful for learners' conceptual understanding as well as improving their performance in geometry. The 
teachers showed positive opinions on the theme of positive attitudes on the use of diagrams in the teaching and learning of geometry. Their opinions ranged $53 \%$ (item 7, Table 1) to $96.7 \%$ (item 10, Table 1) for those who agreed and form 3.3\% (item 10, Table 1) to $47 \%$ (item 7 , Table 1 ) those who disagreed.

The study also sought to find out whether there was a significant difference between rural and urban Zimbabwean teachers' views on the utility value of diagrams in the teaching and learning of geometry. Table 2 displays the Mann-Whitney U test results.

Table 2. Results of Mann-Whitney $U$ test on the utilitarian value of diagrams ( $n=91$ )

\begin{tabular}{|c|c|c|c|c|c|c|c|}
\hline$\overline{Q S N}$ & Teacher & $\mathrm{N}$ & Mean Rank & Sum of Ranks & Mann-Whitney U & Z & $P$ \\
\hline \multicolumn{8}{|c|}{ Utilitarian value } \\
\hline \multirow{3}{*}{13} & Rural & 41 & 46.61 & 1911.00 & 1000.000 & & \\
\hline & Urban & 50 & 45.50 & 2275.00 & & -1.104 & .269 \\
\hline & Total & 91 & & & & & \\
\hline \multirow{3}{*}{5} & Rural & 41 & 46.72 & 1915.50 & 995.500 & & .447 \\
\hline & Urban & 50 & 45.41 & 2270.50 & & -.761 & \\
\hline & Total & 91 & & & & & \\
\hline \multirow{3}{*}{4} & Rural & 41 & 44.61 & 1829.00 & 968.000 & & .249 \\
\hline & Urban & 50 & 47.14 & 2357.00 & & -1.152 & \\
\hline & Total & 91 & & & & & \\
\hline \multirow{3}{*}{9} & Rural & 41 & 44.11 & 1808.50 & 947.500 & & .150 \\
\hline & Urban & 50 & 47.55 & 2377.50 & & -1.438 & \\
\hline & Total & 91 & & & & & \\
\hline \multirow{3}{*}{1} & Rural & 41 & 49.21 & 2017.50 & 893.500 & & .128 \\
\hline & Urban & 50 & 43.37 & 2168.50 & & -1.520 & \\
\hline & Total & 91 & & & & & \\
\hline \multirow{3}{*}{11} & Rural & 41 & 36.44 & 1494.00 & 633.000 & & .000 \\
\hline & urban & 50 & 53.84 & 2692.00 & & -3.911 & \\
\hline & Total & 91 & & & & & \\
\hline \multicolumn{8}{|c|}{ Positive attitude } \\
\hline \multirow{3}{*}{10} & Rural & 41 & 46.72 & 1915.50 & 995.500 & & .447 \\
\hline & Urban & 50 & 45.41 & 2270.50 & & -.761 & \\
\hline & Total & 91 & & & & & \\
\hline \multirow{3}{*}{8} & Rural & 41 & 44.00 & 1804.00 & 943.000 & & .065 \\
\hline & Urban & 50 & 47.64 & 2382.00 & & -1.842 & \\
\hline & Total & 91 & & & & & \\
\hline \multirow{3}{*}{3} & Rural & 41 & 44.00 & 1804.00 & 943.000 & & .065 \\
\hline & Urban & 50 & 47.64 & 2382.00 & & -1.842 & \\
\hline & Total & 91 & & & & & \\
\hline \multirow{3}{*}{12} & Rural & 41 & 42.83 & 1756.00 & 895.000 & & .087 \\
\hline & Urban & 50 & 48.60 & 2430.00 & & -1.711 & \\
\hline & Total & 91 & & & & & \\
\hline
\end{tabular}




\begin{tabular}{|c|c|c|c|c|c|c|}
\hline & Rural & 41 & 50.26 & 2060.50 & 850.500 & .079 \\
\hline \multirow[t]{2}{*}{2} & Urban & 50 & 42.51 & 2125.50 & & -1.759 \\
\hline & Total & 91 & & & & \\
\hline \multirow{3}{*}{6} & Rural & 41 & 53.30 & 2185.50 & 725.500 & .004 \\
\hline & Urban & 50 & 40.01 & 2000.50 & & -2.888 \\
\hline & Total & 91 & & & & \\
\hline \multirow{3}{*}{14} & Rural & 41 & 45.15 & 1851.00 & 990.000 & .740 \\
\hline & Urban & 50 & 46.70 & 2335.00 & & -.331 \\
\hline & Total & 91 & & & & \\
\hline \multirow{3}{*}{7} & Rural & 41 & 46.70 & 1914.50 & 996.500 & .793 \\
\hline & Urban & 50 & 45.43 & 2271.50 & & -.263 \\
\hline & Total & 91 & & & & \\
\hline
\end{tabular}

An examination of the results from the Mann-Whitney $U$ test showed that rural and urban teachers' views on the utilitarian values diagrams in the teaching and learning of geometry on questions $13,5,4,9$, and 1 there was no significant difference. However, on question 11 the results showed that there was a significant difference $(\mathrm{z}=-$ $3.911 ; \mathrm{p}=.00<0.05$ ) on rural and urban teachers' views on teachers' views on the utilitarian values diagrams in the teaching and learning of geometry. The mean rank of rural was 36,44 , while the urban teachers had a mean rank of 53.84 , which indicates that the urban teachers had higher scores than the rural teachers implying that rural and urban teachers' views were different. Similarly, the results from the MannWhitney U test showed that rural and urban teachers' views on positive attitude towards the use of diagrams in the teaching and learning of geometry on question 10, $8,3,12,2,14$ and 7 there was no significant difference. However, on question 6 the results showed that there was a significant difference $(\mathrm{z}=-2.888 ; \mathrm{p}=.004<0.05)$ on rural and urban teachers' views on positive attitude towards the use of diagrams in the teaching and learning of geometry. The mean rank of rural was 53.30, while the urban teachers had a mean rank of 40.01, which indicates that the rural teachers had higher scores than the urban teachers implying that rural and urban teachers' views were different. With respect to questions $13,5,4,9,1,10,8,3,12,2,14$ and 7 , it can be concluded that there was no significant difference on rural and urban teachers' views on both utilitarian value and positive attitudes towards the use of diagrams in the teaching and learning of geometry. 


\subsection{Responses from interviews}

The interview was guided by the following question; what are your views on the use of diagrams in geometry teaching and learning? In general, from this interview question, the teachers conveyed both positive views and negative views on the use of diagrams in the teaching and learning of geometry. The teachers held views such as diagrams that are easy to use for code-switching and for assessing students' understanding of geometry concepts and problem-solving skills. These views are exemplified by the following quotations:

Diagrams convey meaning to geometry concepts; in other words, it helps in code-switching, although some of the students have difficulties in the English language used to teach geometry concepts. I mostly use geometric diagrams when assessing students whether they understand concepts and problem solving. T 1

Geometric diagrams enable learners to notice geometrical properties, verifying logical deductions, representing ideas, and suggesting proofs. T 2

Geometric diagrams illustrate a definition of a statement, making it easy for learners to draw conclusions and solve problems for geometry. T 3

Diagrams in geometry are an aid to proof without words, where diagrams are drawn to illustrate what needs to be proved, and it is a learner-centered approach which makes learners active and problem solvers. T 4

Diagrams are useful because they enable difficult geometric concepts and their processes to be arranged and represented comprehensively, making it easier for students to find solutions to a particular problem. T 5

Generally, the teachers held positive views about the use of diagrams in the teaching and learning of geometry. Diagrams are useful in assessing the students' understanding of geometry concepts as well as helping them with geometry proofs. The positive effect of diagrams on geometry proofs was also highlighted by Bieda (2011). The diagrams make it easier to examine the pertinent information and to notice connections and dependencies in a given problem.

Diagrams, if properly used, they make both teachers and learners actively involved during the teaching and learning process. Active learning is one of the key components learner-centered approaches that are advocated for by social constructivists such as Vygotsky (1978). The use of diagrams in illustrating definitions in geometry is in line with Ding, Jones \& Zhang's (2013) 's word-symbol strategy in which definitions are translated into geometrical symbol language with diagrams that enhance students' understanding of geometry definitions. 
However, the same teachers expressed negative views on the use of diagrams in the teaching and learning of geometry. Their negative views are exemplified by the following quotations:

Geometric diagrams may result in students jumping into conclusions ignoring important information. T 1

Students may rush through a problem and fail to read instructions and given information carefully when using diagrams in geometry. T 2

If the diagrams are not well designed, students may not fully understand the problem that is required to be solved, and misrepresentation of geometry diagrams makes students not to notice the properties of the diagram. Some of the students may treat unnecessary data in the geometric diagram as important, resulting in failing to solve problems. $\mathrm{T} 4$

The responses revealed that when using geometry diagrams to solve problems, students may jump to conclusions ignoring important information. This is in line with Butcher \& Aleven (2008), who noted that if unfocussed attention compromised the performance of learners. One of the mathematics teachers at this school noted that if the diagram in geometry is misrepresented, the user may not be able to notice the properties of the diagram, which can make the user unable to solve problems in geometry, as noted by Jones \& Mooney (2003).

The following question on the interview guide was on how the teachers use the diagrams in the teaching and learning of geometry. The findings showed that teachers' use of diagrams in the teaching of geometry was informed by social constructivist theories that encourage the use of the students' prior knowledge and their cultural environments. Their views are illustrated by the following quotations:

I make use of mapping the relevant diagram features and properties to connect their prior knowledge. T 1

I start from concrete to abstract, for example, using real-world situations like using where trees branches it gives angles, then use diagrams to represent angles. Geometry topics need field learning in order to connect learner's prior knowledge and diagrams. T 2

I make use of the basic properties of the geometric diagram in order to connect the student's foregoing knowledge and diagrams in geometry. $\mathrm{T} 3$.

I normally use learners' everyday life materials and connect to geometry diagrams, for example, using an orange to represent a diagram of a circle, then cut an orange to get sectors of circles then draw to geometric diagrams. T 5 
Most of the geometry teachers under this study have the same idea on how they connect geometry teaching and learning using diagrams to their prior knowledge. They start from concrete to abstract, simple to complex, known to unknown, which is a component of the learner-centered approaches. Those teachers connect prior knowledge of students to geometric diagrams, which enable problem-solving in geometry concepts. Those teachers' views of connecting geometry teaching and learning using diagrams are in line with Fosnot (1996), who was of the view that diagrams are rooted in the philosophy of constructivism as they connect geometry to the real world.

\section{Conclusion}

The results of this study showed that the participants regarded diagrams as useful in the teaching and learning of geometry concepts. Diagrams are important in the teaching and learning of geometry and can be connected to learners' prior knowledge in solving geometry problems. Geometric diagrams can help students acquire important information and critical thinking skills. Diagrams usually display a variety of properties and strategies for problem-solving. However, it was also reported that diagrams could be misleading, resulting in completely wrong solutions. It is recommended that teachers should make use of technology in designing diagrams that can be used in the teaching and learning of geometry. Further research should be carried out on a more extensive scale, including other districts in Zimbabwe, to find the effectiveness of using diagrams in the teaching and learning of geometry concepts and other areas of mathematics.

\section{References}

Abrams, E., Taylor, P.C. \& Guo, C.J. (2013). Contextualizing culturally relevant science and mathematics teaching for indigenous learning. International Journal of Science and Mathematics Education, 11, 1-21.

Aikenhead, G., Calabrese, A. B. \& Chinn, P. (2006). Towards a politics of place-based science education. Cultural Studies of Science Education, 1(2), 403-416.

Alcock, L., \& Simpson, A. (2004). Convergence of sequences and series: Interactions between visual reasoning and the learner's beliefs about their own role. Educational Studies in Mathematics, 57(1), 1-32.

Bailey, M (2013). The Direct and Indirect Paths Impacting Geometry Student Achievement" (2013). Dissertations, Theses and Capstone Projects. Paper 587.

Bieda, K. N. (2011). Middle grades students' emerging beliefs about argumentation. Proceedings of PME 35(2), 153-160. 
Butcher, K. R. \& Aleven, V. (2008). Diagram interaction during intelligent tutoring in geometry: support for knowledge retention and deep understanding. In: Love, B.C., McRae, K., Sloutsky, V.M. (eds.) Proceedings of the 3oth Annual Conference of the Cognitive Science Society, pp. 1736-1741. Cognitive Science Society, Austin.

Chiwiye, T. (2013). Assessment of mathematics and science subjects in Zimbabwe: ZIMSEC Perspective, ZIMSEC.

Dimmel, J. K \& Herbst. P. G. (2015). The Semiotic Structure of Geometry Diagrams: How Textbook Diagrams Convey Meaning. Journal for Research in Mathematics Education, 46(2), 147-195.

Ding, L., Jones, K, \& Zhang, D. (2013). Teaching geometrical theorems in Grade 8 using the 'Shen Tou' method: a case study in Shanghai. In L. Fan et al. (Eds), How Chinese Teach Mathematics. Singapore: World Scientific.

Economic and Social Research Council (2008). Strategic Advisor for the undergraduate teaching quantitative methods (tender document). Swindon: ESRC.

Fosnot, C. (1996). Constructivism: A psychological theory of learning. In Fosnot (Ed), Constructivism: Theory, perspectives and practice. New York: Teachers College Press.

Gagatsis, A., Monoyiou, A, Deliyianni, E., Elia, I., Michael, P., Kalogirou, P., Panaoura, A. \& Philippou, A. (2010). One Way of Assessing the Understanding of A Geometrical Figure. Acta Didactica Universitatis Comenianae Mathematics, 10, 35-50.

Gerdes, P. (2011). African Basketry: Interweaving Art and Mathematics in Mozambique. In Bridges Coimbra Mathematics, Music, Art, Architecture, Culture Conference Proceedings (pp. 9-16).

Haj-Yahya, A., \& Hershkowitz, R. (2013). When visual and verbal representations meet the case of geometrical figures. Proceedings of PME 37(2), 409-416.

Herbst, P. (2004). Interactions with diagrams and the making of reasoned conjectures in geometry. ZDM, 36(5), 129-139.

Herbst, P., \& Arbor, A. (2004). Interactions with diagrams and the making of reasoned conjectures in geometry. ZDM, 36(5), 129-139.

Jones, K. and Mooney, C. (2003). Making Space for Geometry in Primary Mathematics, Open University Press, London.

Jones, K. (2013). Diagrams in the teaching and learning of geometry: some results and ideas for future research. Proceedings of the British Society for Research into Learning Mathematics, 33(2), 37-42.

Jones, W.P. \& Scott, A.L. (2013). Optimal number of questionnaire response categories: More may not be better". SAGE Open, 3(2), 1-10.

Jones, K., \& Tzekaki, M. (2016). Research on the teaching and learning of geometry. In A. Gutiérrez, G. Leder \& P. Boero (Eds.), The Second Handbook of Research on the Psychology of Mathematics Education: The Journey Continues (pp. 109-149). Rotterdam: Sense. The published version is available at: http://dx.doi.org/10.1007/978-94-6300-561-6_

Jones, K. (2001). Spatial thinking and visualization. In K. Jones (Ed.). Teaching and Learning Geometry (pp. 55-56). London GB: Royal Society.

Jones, K., Fujita, T., \& Kunimune, S. (2012). Representations and reasoning in 3-D geometry in lower secondary school. Proceedings of PME 36(2), 339-346.

Leung, F., \& Park, K. (2009). The influence of language on the conception of geometric figures. Proceedings of PME 33(1), 418.

Konyalioglu, A. C., Isik, A., Kaplan, A., Hizarci, S., \& Durkaya, M. (2011). Visualization approach in teaching process of linear algebra. Procedia-Social and Behavioral Sciences, 15, 4040-4044. 
Koedinger, K. R., \& Anderson, J. R. (1990). Abstract planning and perceptual chunks: Elements of expertise in geometry. Cognitive Science, 14(4), 511-550.

https://doi.org/10.1207/s15516709cog1404_2

Mashingaidze, S. (2012). The Teaching of Geometric (Isometric) Transformations at Secondary School Level: What Approach to Use and Why? Asian Social Science, 8 (15), 197-210. https://doi.org/10.5539/ass.v8n15p197

Matos, J. F., \& Rodrigues, M. (2011). Proof in classroom social practice. Proceedings of PME 35(3), 177-184.

National Council of Teachers of Mathematics. (2000). Principles and standards for school mathematics. Reston, VA: Author.

Ndinda, M. D (2016). An analysis of the factors influencing achievement in mathematics geometry among secondary school students in Makadara Sub-County, Nairobi County. http://irlibrary.ku.ac.ke/handle/123456789/15293

Novick, L. R. (2004). Diagram literacy in preservice math teachers, computer science majors, and typical undergraduates: The case of matrices, networks, and hierarchies. Mathematical thinking and learning, 6(3), 307-342.

Pakang, J., \& Kongtaln, P. (2007). Creative thinking and mathematics learning about circle of ninth-grade students through art work. Proceedings of PME 31(1), 271.

Prusak, N., Hershkowitz, R., \& Schwarz, B. B. (2012). From Visual Reasoning to Logical Necessity through Argumentative Design. Educational Studies in Mathematics, 79(1), 19-40.

Puphaiboon, K., \& Woodcock, A. (2005). Diagram design method to enhance mathematical learning. In Contemporary Ergonomics 2005. Proceedings of the International Conference on Contemporary Ergonomics (CE2OO5). Hatfield, UK: Taylor \& Francis.

Purchase, H. (2014). Twelve years of diagrams research. Journal of Visual Languages \& Computing, 25(2), 57-75. https:doi.org/10.1016/j.jvlc.2013.11.004

Safuanov, I. S. (2007). Genetic approach to teaching geometry. Proceedings of PME, 3(4), 145152.

Sjøberg, S., \& Schreiner, C. (2005). How do learners in different cultures relate to science and technology? Asia-Pacific Forum on Science Learning and Teaching, 6(2), 1-16.

Small, M. (2012). Visual reasoning K-12. Ontario Mathematics Gazette, 51(1), 21-24.

Telima, A. (2011). Problems of teaching and learning geometry in secondary schools in Rivers State, Nigeria. International Journal of Emerging Science, 1(2), 143-152. http://hdl.handle.net/1893/26189

Üstün, I., \& Ubuz, B. (2004). Student's development of geometrical concepts through a dynamic learning environment. Paper presented at the The 10th International Congress on Mathematics Education. http://www.icme-10.dk/index.html

Watson, A., Jones, K., \& Pratt, D. (2013). Key ideas in teaching mathematics: Research-based guidance for ages 9-19. Oxford, UK: Oxford University Press.

Yelland, N \& Masters, J. (2007). Rethinking scaffolding in the information age, Computers \& Education 48, (2007), 362-382

Zodik, I. \& Zaslavsky, O. (2007). Is visual example in geometry always helpful? In Woo, J. H., Lew, H. C., Park, K. S. \& Seo, D. Y. (Eds.). Proceedings of the $31^{\text {st }}$ Conference of the International Group for the Psychology of Mathematics Education, 4, 265-272.

Zimbabwe Ministry of Primary and Secondary Education New Curriculum Framework (2016). 2015-2022 Handbook. Harare. Government Printers.

Zinyeka, G. (2016). The epistemological basis of indigenous knowledge systems in science education. University of Pretoria. URI: http://hdl.handle.net/2263/52979 